\title{
Peste des Petits Ruminants (PPR) in Ethiopia: Analysis of a national serological survey
}

\author{
Agnès Waret-Szkuta*1,2, François Roger ${ }^{2}$, David Chavernac², \\ Laikemariam Yigezu $^{3}$, Geneviève Libeau ${ }^{2}$, Dirk U Pfeiffer ${ }^{1}$ and Javier Guitián ${ }^{1}$
}

Address: ${ }^{1}$ Epidemiology Division, Department of Veterinary Clinical Sciences, The Royal Veterinary College, Hawkshead Lane, North Mymms, Hatfield, Herts. AL9 7TA, UK, ${ }^{2}$ CIRAD, Campus International de Baillarguet, 34398 Montpellier Cedex 5, France and ${ }^{3}$ FAO, Addis Ababa, Ethiopia

Email: Agnès Waret-Szkuta* - awaret@rvc.ac.uk; François Roger - francois.roger@cirad.fr; David Chavernac - david.chavernac@cirad.fr; Laikemariam Yigezu - laike@siga.org.et; Geneviève Libeau - genevieve.libeau@cirad.fr; Dirk U Pfeiffer - pfeiffer@rvc.ac.uk; Javier Guitián - JGuitian@rvc.ac.uk

* Corresponding author

Published: 12 September 2008

BMC Veterinary Research 2008, 4:34 doi:10.1 186/1746-6148-4-34
Received: 22 April 2008

Accepted: 12 September 2008

This article is available from: http://www.biomedcentral.com/I746-6/48/4/34

(c) 2008 Waret-Szkuta et al; licensee BioMed Central Ltd.

This is an Open Access article distributed under the terms of the Creative Commons Attribution License (http://creativecommons.org/licenses/by/2.0), which permits unrestricted use, distribution, and reproduction in any medium, provided the original work is properly cited.

\begin{abstract}
Background: Peste des petits ruminants (PPR) is a contagious viral disease of small ruminants in Africa and Asia. In 1999, probably the largest survey on PPR ever conducted in Africa was initiated in Ethiopia where 1365 I serum samples from 7 out of the II regions were collected and analyzed by competitive enzyme-linked immunosorbent assay (cELISA). The objective of this paper is to present the results of this survey and discuss their practical implications for PPR-endemic regions.

Methods: We explored the spatial distribution of PPR in Ethiopia and we investigated risk factors for positive serological status. Intracluster correlation coefficients $(\rho)$, were calculated for 43 wereda (administrative units).

Results: Seroprevalence was very heterogeneous across regions and even more across wereda, with prevalence estimates ranging from $0 \%$ to $52.5 \%$. Two groups of weredas could be distinguished on the basis of the estimated $\rho$ : a group with very low $\rho(\rho<0.12)$ and a group with very high $\rho$ $(\rho>0.37)$.

Conclusion: The results indicate that PPRV circulation has been very heterogeneous, the values for the $\rho$ may reflect the endemic or epidemic presence of the virus or the various degrees of mixing of animals in the different areas and production systems. Age appears as a risk factor for seropositive status, the linear effect seeming to confirm in the field that PPRV is highly immunogenic. Our estimates of intracluster correlation may prove useful in the design of serosurveys in other countries where PPR is of importance.
\end{abstract}

\section{Background}

Peste des Petits Ruminants (PPR) is a severe and highly infectious viral disease of small ruminants. The PPR virus (PPRV) belongs to the genus Morbillivirus in the family Paramyxoviridae. It is closely related to the rinderpest virus of bovines and buffaloes, distemper virus of dogs and other wild carnivores, human measles virus and Morbilliviruses of marine mammals [1-4]. In small ruminants, infection by PPRV is characterized by sudden depression, fever, nasal and ocular discharge, diarrhoea and occasion- 
ally death. Morbidity in the range of 10 to $80 \%$ and mortality proportions from 0 to $90 \%$ have been reported. The wide range of reported values is likely to be influenced by differences between species (sheep or goats), production systems and levels of natural or acquired immunity [5$10]$.

PPR was first described in West Africa in 1942 [11]. Nowadays the disease is recognized as responsible for mortality and morbidity across most of the sub-Saharan African countries situated north of the equator, in the Arabian Peninsula, in India and in numerous other countries in Asia [6,12-14]. Although nationwide serosurveys have been conducted in countries such as the sultanate of Oman, Turkey, Jordan and India, information on the frequency and distribution of PPR is often lacking when control or eradication campaigns are initiated [15-18]. Control of PPR in endemic areas relies mainly in vaccination $[19,20]$. In 1989 a homologous vaccine that induces lifelong immunity in both sheep and goats was developed [6,21-23]. The vaccine is innocuous on pregnant sheep and goats at any stage of gestation and induces the production of colostral anti-PPR antibodies that have been found in kids up to 3 months old $[6,23]$.

Ethiopia has the most important livestock population in Africa and is ranked $9^{\text {th }}$ in the world [24]. The livestock sub sector accounts for $40 \%$ of the agricultural gross domestic product (GDP) and 20\% of the total GDP (Aklilu Y. An audit of livestock marketing status in Kenya, Ethiopia and Sudan. PACE/OUA/IBAR, 2002) without considering the livestock contribution in terms of traction power, fertilizing and mean of transport. Sheep and goat populations are estimated to be 20.7 million and 16.4 million respectively [25]. Sheep and goats contribute $25 \%$ of the meat domestically consumed with a production surplus mainly being exported as live animals [26,27]. Both species also contribute $50 \%$ of the domestic needs in wool, about $40 \%$ of skins and $92 \%$ of the value of hides and skin exported [28]. The annual production of sheep and goat meat is estimated as 56560 and 28650 tonnes respectively [24]. PPR was clinically suspected for the first time in Ethiopia in 1977 in a goat herd in the Afar region, East of the country $[9,29]$. Clinical and serological evidence of its presence has been reported by Taylor (1984) and later confirmed in 1991 with cDNA probe in lymph nodes and spleen specimens collected from an outbreak in a holding near Addis Ababa [29]. During the nineties, several small serological surveys were conducted, mainly east of an imaginary line that would run parallel to the Rift valley and pass through Addis Ababa. In 1994 Roger and Bereket (CIRAD-EMVT report $\mathrm{n}^{\circ}$ 96006, Montpellier, 1996 ) found seroprevalences of up to $33 \%$ in sheep and $67 \%$ in goats near selected urban areas. In 1996 Gelagay found that $14.6 \%$ of sheep sampled along 4 roads from
Debre Berhan to Addis Ababa were seropositive [30]. In 1997 Yayerade found up to $100 \%$ of seropositive individuals in groups of adult male sheep and animals that survived suspected outbreaks. Although these studies provide very limited and potentially biased information about the frequency and distribution of PPR in Ethiopia, they clearly suggest that the virus has been circulating extensively among the small ruminant population of Ethiopia during the nineties. Based on the reported morbidity and mortality of the infection and the size and structure of the small ruminant sector it is likely that PPR became one of the most economically important livestock diseases in the country [12,31].

In 1999, a serological survey on PPR was conducted in Ethiopia with the aim of informing a subsequent vaccination campaign which would be the first large scale vaccination campaign against PPR in the country. As part of the survey, a total of 13753 sheep and goats were sampled. To our knowledge, this is the largest serological survey on PPR ever conducted in Africa. The objective of this paper is to describe the results of this survey and discuss its practical implications.

\section{Methods \\ Administrative structure and distribution of small ruminants in Ethiopia}

The Ethiopian administrative structure has frequently been subject to modification. To date there are 11 Regions or States or Kelel composed of 71 zones. These zones include about 546 districts or wereda or woreda. Each wereda is composed of kebelles or Peasant Associations that are an aggregation of got, a got being a group of 3 to 5 villages although the difference between got and village is sometimes unclear in the field [25]. The very diverse relief of the country determines several geoclimatic zones. The central part is characterized by mountainous massifs and covers half of the territory. It is a zone of Highlands ranging from 2300 to $3500 \mathrm{~m}$ called Dega surrounded by a temperate transition zone between 1500 and $2300 \mathrm{~m}$ called Woinadega that dives in the central Rift Valley towards the south west. East the tectonic deflection opens on the lowland areas Bereha and Kola (0 to $1200 \mathrm{~m}$ ), zones of pastoral nomadic livestock husbandry [32].

In 1995 about three quarters of the sheep stock was located in the Ethiopian highlands (> $1500 \mathrm{~m}$ ) [33]. A recent report (Aklilu Y. consultancy report USAID/Ethiopia and EGAT Office of USAID/Washington, 2005) suggests that nowadays around half of the sheep are kept in the highlands and half in the lowlands.

\section{The 1999 Survey}

According to a report of the Ethiopian Ministry of Agriculture and Rural Development of 2005 the serological sur- 
vey was initiated in 1999 to determine the distribution of PPR across the country and to identify areas of increased risk. Compared to the previous studies the geographical coverage is extended to north and western parts of the country. The objective of the survey was to inform the design of a strategy for cost effective control of the disease. The survey was implemented as a subcomponent of the animal health component under the National Livestock Development Project (NLDP) of the Ethiopian Ministry of Agriculture. This project started in 1999 and was financed by the African Development Bank (ADB). The original plan was to collect $8000-12000$ sera samples through 7 regional veterinary laboratories located in 7 regional states to inform a 3 year vaccination campaign to be started in 2004. Thus vaccination would be implemented in those wereda identified by the regional states as endemic for PPR as well as in the neighbouring wereda.

Multistage sampling was the chosen sampling strategy, with 4 hierarchical stages as illustrated in Table 1 . The first level of selection was the region; only those regions with a veterinary laboratory ( 7 out of the 11 regions) were selected. Within each of the selected regions (Afar, Amhara, Benishangul Gumuz, Oromia, SNNPR, Somali, Tigray) weredas, kebelles and villages were randomly selected (Epidemiology unit, Ministry of Agriculture and Rural Development personal communication). Within each of the selected villages, 20 animals (either sheep or goats) were supposed to be randomly selected but were most probably purposively selected because of field and time constraints although we have not been able to completely ascertain the details of the selection process (Laikemariam Yigezu, former PACE coordinator and head of Microbiology unit at the Sebeta laboratory, personal communication).

\section{Laboratory techniques}

Serum samples were analyzed by the National Animal Health Research Center (NAHRC, Sebeta, Ethiopia) using a competitive ELISA kit according to the instructions of the manufacturer (Institute for Animal Health, Pirbright Laboratory, UK). The ELISA micro-plates were read with an immunoskan reader (Flow laboratories, UK) with an inference filter of $492 \mathrm{~nm}$. The reader was connected to a computer loaded with ELISA Data Information (EDI) software (FAO/IAEA, Vienna, Austria), which was used to automate the reading and calculation of the percentage of inhibition (PI) values. The OD (Optical Density) values were converted to percentage inhibition using the following formula:

$$
\begin{gathered}
\mathrm{PI}=100-(\mathrm{OD} \text { control or test serum/OD monoclonal } \\
\text { control }) * 100
\end{gathered}
$$

The samples with PI > 50\% (cut-off) were considered as positives.

\section{Data management}

The data were entered and stored electronically in Microsoft Office Access 2003. The fields included in the database are presented in Table 2. Laboratory results and field information collected during the sampling were entered into the database. When age was given as a binary variable (young vs. adult; $\mathrm{n}=157$ entries), it was considered to be a missing value. When age was given as number of months or years of age (values ranging from 6 months to 10 years old; $\mathrm{n}=465$ ) the original variable was recategorized into 4 categories $(<1 ; 1<2 ; 2<3 ;>=3)$ to match with the categories given for the remaining 4181 animals for which age was given using these four categories.

\section{Data analysis and spatial description}

Descriptive statistics of the studied variables were obtained. Within each wereda, the following parameters were obtained:

- seroprevalence (number of positive valid samples/ number of individuals sampled in the wereda)

- intra-kebelle correlation coefficient ( $\rho$ ) for the 43 weredas for which information about the kebelle of origin of the samples was available calculated as:

Table I: Structure of the different administrative levels of sampling

\begin{tabular}{cccc}
\hline Included in the above administrative level & Region (Ref) & wereda & kebelle \\
\hline Total & 7 & 84 & 9 \\
Mode & & 5 & 5 \\
Average & 12.14 & $4.98^{*}$ & $4.45^{* *}$ \\
Range & $8-19$ & $2-9$ & $1-5$ \\
\hline
\end{tabular}

\footnotetext{
*average number of kebelle per wereda where kebelle level was available

**average number of villages per kebelle where village level was available

The table shows the 4 administrative levels of sampling in the 1999 national serological survey on PPR in Ethiopia. The first level of selection was the region with 7 regions selected. Within each of the regions weredas, kebelles and villages were randomly selected. For each level the mode, average and range of units included in the above administrative level are presented.
} 
Table 2: List of relevant variables included in the database along with the number of observations available

\begin{tabular}{ccc}
\hline Variable & Number of samples for which it was recorded & \% of samples for which it was recorded \\
\hline Localisation & 13651 & 100 \\
Region & 13613 & 99.7 \\
Wereda & 9328 & 68.3 \\
Kebelle & 980 & 7.2 \\
Village & 13651 & 100 \\
\hline Species $^{\mathbf{a}}$ & 4648 & 34 \\
Age $^{\mathbf{a}}$ & 5868 & 43 \\
Sex $^{\mathbf{a}}$ & & 100 \\
Results $_{\text {OD }}$ & 13651 & 100 \\
PI & 13651 & 100 \\
\hline
\end{tabular}

a: categories defined in Table 4

For each variable recorded during the 1999 serological survey on PPR in Ethiopia and stored in the database, the number of samples for which information was recorded and the \% out of the total number of samples it represents are shown.

$$
\rho=\frac{\sigma^{2}(b)}{\sigma^{2}(b)+\sigma^{2}(w)}
$$

Where:

$$
\begin{gathered}
\text { Between-group variance }: \sigma^{2}(b)=\frac{\sum_{i=1}^{K} n_{i}\left(\bar{x}_{i}-\bar{x}\right)^{2}}{(K-1)} \\
\text { Within-group variance : } \sigma^{2}(w)=\frac{\sum_{i=1}^{K} \sum_{j=1}^{n_{i}}\left(x_{i j}-\bar{x}_{i}\right)^{2}}{(n-K)}
\end{gathered}
$$

For a wereda in which $K$ kebelles are sampled with $n_{i}$ samples obtained from kebelle $i$

Chloropleth maps were produced using ArcGIS version 9.1 (ESRI, Redlands, California) to show the distributions of i) seroprevalence by wereda and ii) intra-kebelle correlation coefficient.

The hypotheses that species, age group and sex significantly differed between positive and negative animals were first tested in a univariate analysis by means of 2 tailed chi-squared tests without adjustment for clustering of observations within wereda. In a second step, a logistic regression model was used to assess the association between the potential risk factors sex, age and species and the outcome variable PPR serological status. The three independent variables were forced into the model. Wereda was included as a random effect to account for clustering within weredas. In the multivariate analysis, the first two age categories (less than 1 year and between 1 and 2 years) were collapsed into a single category due to the low numbers of observations in the " $<1$ year" group. Associations were deemed significant when $\mathrm{P} \leq 0.05$ by Wald test. The reliability of the regression coefficient estimates was assessed by testing the sensitivity of the quadrature approximation.

To assess whether the intra-cluster correlation was associated with the magnitude of the serological response of the animals in the wereda, we calculated non-parametric correlations (Spearman) between $\rho$ and the $50^{\text {th }}, 75^{\text {th }}$ and $90^{\text {th }}$ percentiles of the ELISA inhibition percentage and between $\rho$ and the seroprevalence.

Statistical analyses were conducted using SPSS 15.0 for Windows $^{\varpi}$ (SPSS Inc., Chicago, Illinois) and Stata 9.0 (Stata Corporation, College Station, TX).

\section{Results}

\section{Seroprevalence of PPR in Ethiopia}

One hundred and two individual observations were dropped because of missing serological results. The remaining 13651 individual observations were used in the analysis. The variables included in the dataset and the number of observations for which each variable was available are presented in Table 2. The periods of sampling, submission and analysis, based on the samples for which dates were available, lasted from 26 March 1999 to 5 June 2002, 19 October 1999 to August 2002 and 6 February 2001 to 13 February 2003, respectively.

The distribution of samples across regions and the prevalence per region are presented in Table 3. 
Table 3: Prevalence of PPR in the seven surveyed regions

\begin{tabular}{lcc}
\hline Regions & $\begin{array}{c}\text { Number of samples collected in each region and \% of the whole } \\
\text { survey }\end{array}$ & Prevalence with 95\% Confidence Intervals \\
\hline Afar & $1653(12.1 \%)$ & $15.3 \%(13.6-17.0)$ \\
Amhara & $5992(43.9 \%)$ & $4.6 \%(4.0-5.1)$ \\
Benishangul Gumuz & $729(5.3 \%)$ & $8.0 \%(6.0-9.9)$ \\
Oromia & $2290(16.8 \%)$ & $1.7 \%(1.2-2.2)$ \\
SNNPR & $1622(11.9 \%)$ & $1.8 \%(1.1-2.4)$ \\
Somali & $465(3.4 \%)$ & $21.3 \%(17.6-25.0)$ \\
Tigray & $900(6.6 \%)$ & $15.3 \%(13.6-15.9)$ \\
Total & $13651(100 \%)$ & $6.4 \%(6.0-6.8)$
\end{tabular}

Number of samples collected and prevalence of PPR in each of the surveyed regions. In brackets: $\%$ of the whole survey they represent and $95 \%$ confidence intervals.

There were large variations between the different regions in the distribution of the samples. Most of the samples have been collected in the northern part of the country and particularly in the Amhara region (43.9\% of total samples collected). In regions like Somali or Afar there are about the same numbers of samples collected per wereda whereas in Amhara differences across wereda are more pronounced perhaps as a result of accessibility constraints. Similarly, few samples were collected in 6 weredas of Tigray region that had never been surveyed before.

There were important differences in the prevalence across regions, with the Oromia region showing the lowest prevalence $(1.7 \%, 95 \%$ CI: $1.2-2.9)$ and the Somali region the highest $(21.3 \%$, 95\% CI: $17.6-38.8)$ (Table 3$)$. The variations are even more important for prevalence at the wereda level as shown in Figure 1. Wereda level prevalence estimates ranged from $0 \%$ for Guba in Benishangul region or $\mathrm{Ab}$ Ala in Afar region to $52.5 \%$ for Dolo Odo in Somali region. Wereda with the higher prevalence levels seem to be mainly those in areas of low altitudes where pastoral management systems prevail over sedentary ones.

\section{Risk factors for positive serological status against PPR}

Descriptive statistics for the variables under study and the results of univariate comparisons are presented in Table 4. The proportions of seropositive animals significantly differ between species, age groups and sex categories. In the univariate analysis, sheep were 4.4 more likely and goats 5 times more likely to be seropositive for PPR than shoats (category combining both sheep and goats). Females were 1.3 times more likely to be seropositive than males. Regarding the age of the animals, none of the 41 animals younger than 1 year were positive. The highest prevalence was observed among animals older than 3 years, $12.6 \%$ of which were seropositive.

Results of the logistic regression assessing the relationship between species, age and sex and serological status are presented in Table 5 . The only factor significantly associated with the odds of positive serological status was the age of the animal. Increasing age was associated with an increasing odds of seropositive status, with animals over 3 years old having almost twice the odds of been positive than animals under 2 years old.

As expected, there was strong evidence of significant intrawereda correlation (intra-cluster correlation $\rho=0.36$; $\mathrm{P}<$ 0.001). Despite the large number of observations per wereda (average of 166 animals) and the large intra-wereda correlation there was no evidence of unreliability of the quadrature approximation when estimates obtained using different numbers of cutpoints were compared.

\section{Intracluster correlation coefficient $(\rho)$}

The 43 weredas for which the intracluster correlation coefficient $(\rho)$ was calculated included between 2 and 9 kebelles each (median $=5$ ) and these kebelles included between 15 and 180 individual animals each (median = 40). The estimated intra-cluster correlation coefficients are presented in Figure 2. Median $\rho$ was 0.029. Although the values seemed very heterogeneous, two groups can be clearly distinguished: One including nearly $80 \%$ of the weredas $(34 / 43)$ with very low values of $\rho(\rho<0.12)$ and the other with $9.3 \%(4 / 43)$ of the weredas showing a strong intracluster correlation, $\rho>0.37$.

Figure 3 shows the geographical distribution of the values for $\rho$ by wereda. The map shows higher values for the correlation coefficient in the north of the country. The intrakebelle correlation coefficient was highly correlated with the inhibition percentages among the animals sampled in the wereda: Spearman rank correlation coefficients of 0.45 $(P=0.003)$ with the median inhibition percentage, 0.45 $(P=0.002)$ with the $75^{\text {th }}$ percentile of the inhibition percentage and $0.61(\mathrm{P}<0.001)$ with the $90^{\text {th }}$ percentile of the inhibition percentage. The intra-kebelle correlation coefficient was also highly correlated with the sero-prevalence found for each wereda: Spearman rank correlation coefficient of $0.67(\mathrm{P}<0.001)$. 


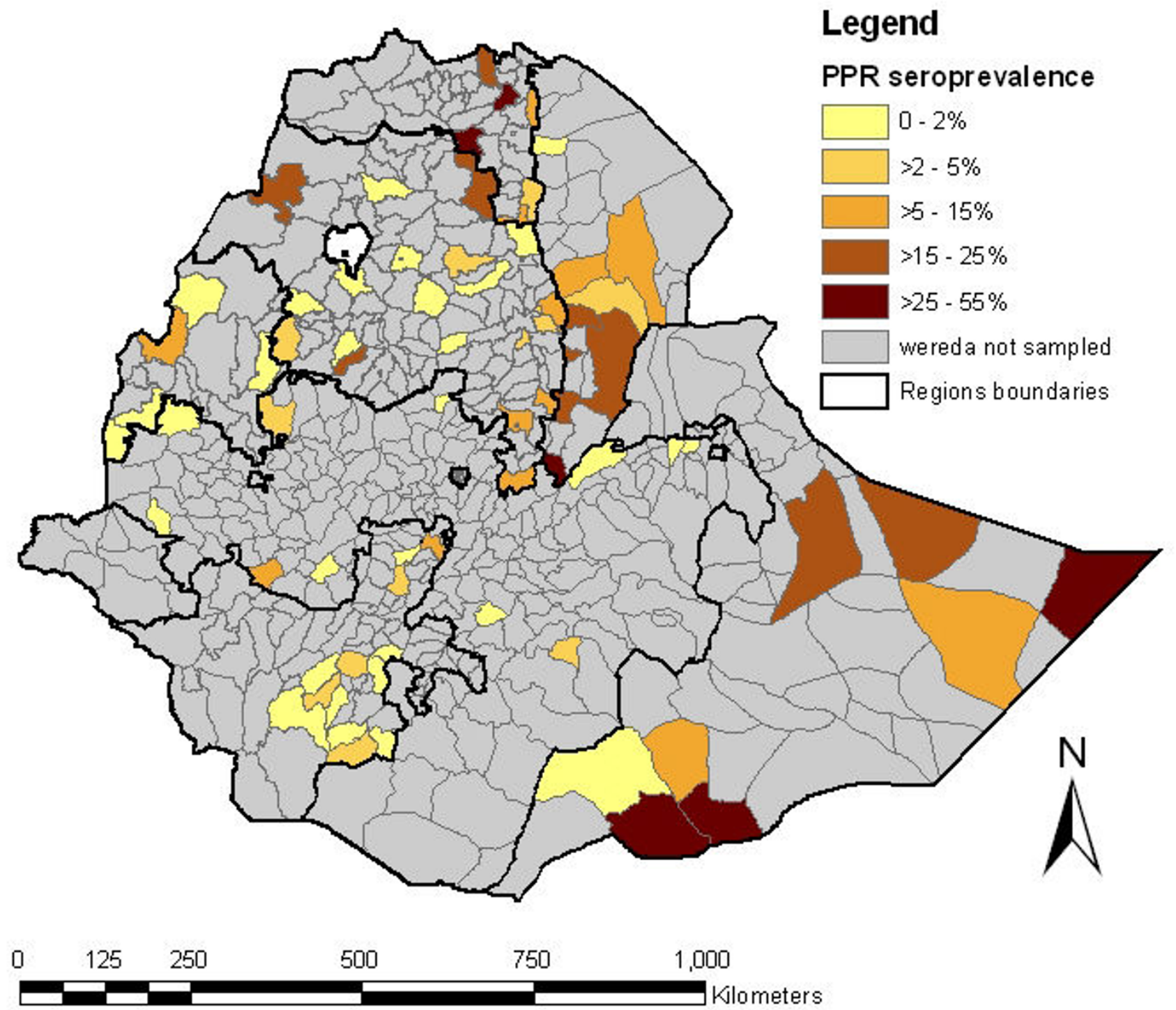

Figure I

Seroprevalence of PPR across wereda in Ethiopia. Administrative map of Ethiopia indicating the regions and weredas boundaries. For each wereda seroprevalence of PPR was calculated by dividing the number of positive valid samples by the number of individual sampled in the wereda. As the colour gets browner higher is the seroprevalence found in the area. In grey, wereda for which no data was available.

\section{Discussion}

Although estimates have to be interpreted with caution because it had not been possible to ensure that random selection was used at all sampling stages, the results indicate that PPR has been circulating in most of the country before large vaccination campaigns were implemented. Lack of large scale vaccination campaigns before the survey was conducted suggests that our seroprevalence estimates are likely to reflect infection [31]. Given the sensitivity and specificity of the test our results are likely to overestimate, slightly, the true proportion of seropositive animals $[34,35]$. On the other hand, by using the results of an imperfect test as indicators of true infection we are probably underestimating the true values of rho [36]. Despite an overall frequency of $6.4 \%$, the seroprevalence of PPR was above $50 \%$ in some weredas. PPRV circulation before 2000 has been heterogeneous: areas of low altitudes appear to have suffered more from infection than areas of highlands. Reasons for this may be related to different production systems with exchanges and move- 
Table 4: Descriptive statistics of qualitative variables and univariate associations with seropositive status against PPR (two-tailed $P$ values for the $\chi^{2}$ - test of association).

\begin{tabular}{|c|c|c|c|c|c|}
\hline Variable & Description & $\mathbf{N}$ & $\%$ of factor & $\%$ positive & $\mathbf{P}$ \\
\hline \multirow[t]{5}{*}{ Species } & & 13651 & 100 & & $<0.001$ \\
\hline & Sheep & 4211 & 31 & 8.3 & \\
\hline & Goats & 4585 & 33.5 & 9.4 & \\
\hline & Shoats* & 4855 & 35.5 & 1.9 & \\
\hline & Not available & 1000 & 10 & & \\
\hline \multirow[t]{6}{*}{ Age } & & 4648 & 34 & & 0.003 \\
\hline & Under I year old & $4 I$ & 0.9 & 0 & \\
\hline & Between 1 and 2 years old & 392 & 8.4 & 10.5 & \\
\hline & Between 2 and 3 years old & 2014 & 43.3 & 9.7 & \\
\hline & Over 3 years old & 2201 & 47.4 & 12.6 & \\
\hline & Not available & 9003 & 66 & & \\
\hline \multirow[t]{4}{*}{ Sex } & & 5868 & 43 & & 0.013 \\
\hline & Males & I 007 & 17.2 & 7.0 & \\
\hline & Females & 4861 & 82.8 & 9.4 & \\
\hline & Not available & 7783 & 57 & & \\
\hline
\end{tabular}

* Sheep and goats not being distinguished

Results of 2-tailed chi-squared tests of the hypothesis that species, age group and sex differed between positive and negative animals. A description of each variable is presented including the number and \% of each category in the sampled population and the \% of positive. The proportions of seropositive animals significantly differ between species, age groups and sex categories $(P$-value $(P)<0.05)$.

ments in areas of lowlands being more frequent and involving larger numbers of animals. In Ethiopia small ruminants mainly thrive on free range pasture lands, shrubs and forest grounds. Agro climatic conditions influence the availability of these resources and the movement of animals becomes necessary in order to ensure the pro-

Table 5: Results of a logistic regression of sex, age and species on serological status against PPR with wereda as random effect.

\begin{tabular}{cccc}
\hline Variable & OR & $\mathbf{P}$ & $\mathbf{9 5 \%} \mathbf{C l}$ \\
\hline $\begin{array}{c}\text { Sex } \\
\text { male } \\
\text { female }\end{array}$ & $\begin{array}{c}\text { ref } \\
1.15\end{array}$ & 0.37 & $0.85-1.54$ \\
\hline $\begin{array}{c}\text { Age } \\
<2\end{array}$ & ref & & \\
$2-3$ & 1.27 & 0.23 & $0.86-1.88$ \\
$>3$ & 1.78 & $<0.01$ & $1.20-2.62$ \\
\hline $\begin{array}{c}\text { Species } \\
\text { sheep } \\
\text { goat } \\
\text { shoat }\end{array}$ & ref & & \\
& 1.08 & 0.50 & $0.86-1.35$ \\
& 1.42 & 0.51 & $0.50-4.04$
\end{tabular}

Results of the logistic regression model used to assess the association between the potential risk factors sex, age and species and the outcome variable PPR serological status. Wereda is included as a random effect to account for clustering within weredas. The only factor significantly associated with the odds of positive serological status is the age of the animal $(P<0.01)$. Animals over 3 years old have almost twice the odds of been positive than animals under 2 years old. vision of fodder and water. This is particularly important during the dry season and in low altitude areas where resources are scarce. In addition, animals are exchanged between households and flocks as a result of social practices and changes in economic conditions that exhibit seasonal patterns. The seasonality of animal movements could partly explain the occurrence of the disease in Ethiopia mainly between the months of March and June $[7,17,31]$.

Although the overall seroprevalence of PPR in Ethiopia appears to be low compared, for example, to the $22.4 \%$ reported in Turkey and 33\% in India, it is difficult to draw any conclusions because of the differences in sampling procedures in the different studies that affect their representativeness [16,17]. However, a common feature described by the respective authors are heterogeneities, possibly related to agro-climatic and socioeconomic factors.

Age appears to be a risk factor for seropositive status, and its linear effect suggests that PPRV is highly immunogenic, naturally infected animals remaining positive for a long time.

The intra-kebelle correlation coefficient was found to be very low in most wereda with a small number of them showing high values. Differences in biological factors probably explain this variability. One hypothesis could be the past or recent circulation of PPRV reflected by a low or 


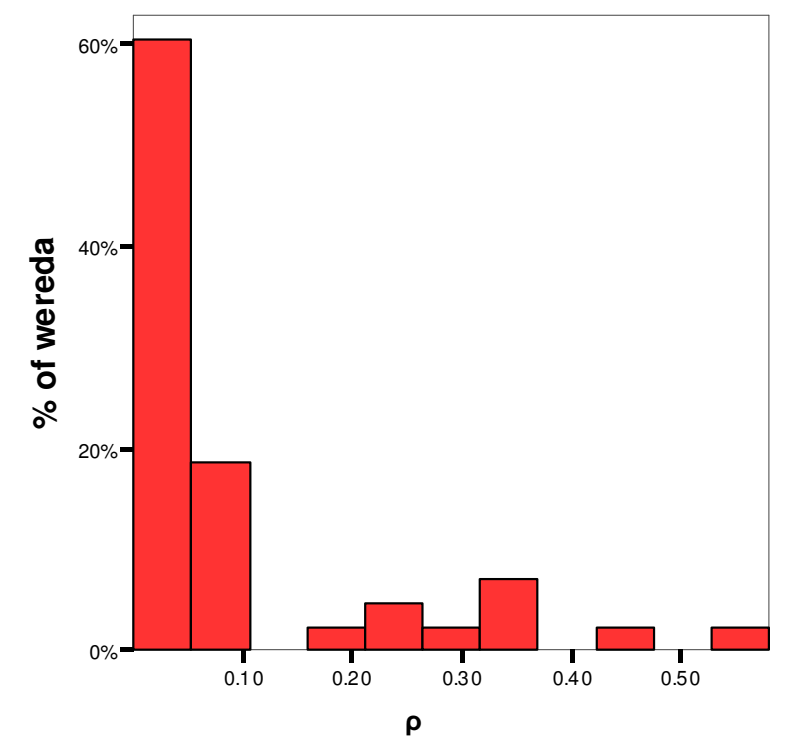

Figure 2

Distribution of the correlation coefficient $(\rho)$ across wereda. Histogram showing the values of the intra-cluster correlation coefficient calculated for 43 weredas for which information about the kebelle of origin of the samples was available as indicated in the Methods section. Two groups can be distinguished: one including almost $80 \%$ of the weredas with low values of $\rho(\rho<0.12)$ and the other with $9.3 \%$ of the weredas showing a strong intracluster correlation $(\rho>$ 0.37).

a high value of $\rho$, respectively, along with a low or high seroprevalence. Assuming that a high inhibition percentage could reflect recent infection, the strong correlation between $\rho$ and inhibition percentage would be consistent with the interpretation of high $\rho$ as being indicative of current or epidemic presence of the virus in a few kebelles within the wereda. This correlation then diminishes with time, diluting itself in a wereda as a consequence of a relatively rapid turnover of small ruminants (3 years), PPRV being highly immunogenic and that these are serological results. Considering that PPR is as a highly contagious disease and that both the within-and between-kebelle spread of infection determine $\rho$, the low value in certain weredas could also be attributed to weredas where animals of different kebelles mix a lot at market points or at water sources. The absence of an obvious spatial pattern in the distribution of $\rho$ may reflect that spread of the disease has mainly occurred within individual wereda as opposed to large scale outbreaks involving several contiguous wereda.

Probabilistic sampling is a challenging task in a country with an infrastructure such as Ethiopia, since large areas have to be covered which are not easily accessible. More- over, sampling frames of lower administrative units are often not available at central level. Under these circumstances, multi-stage sampling strategies such as the one used in the current study are the best option. Despite the random selection of weredas within regions, kebeles within weredas and villages within kebeles there is still potential for bias influencing our results due to non-random selection of regions and animals within villages. Although the large variation of values of $\rho$ highlights the limitation of using a summary measure of $\rho$ for a whole country as a basis for a sampling design, our estimates can inform the design effects needed to adjust for cluster sampling in future surveys on PPR in regions with similar production systems. As an example, if we consider the median $\rho=$ 0,029 , the standard sample size calculations using simple random sampling with $95 \%$ confidence interval for an estimated prevalence of $5 \%$ and an accepted error of $1 \%$ needs to be inflated by a factor of: $D=1+0,029(n-1), n$ being the average cluster size and $\mathrm{D}$ the design effect. That accommodates for the lack of independence between small ruminants belonging to a given kebelle [37].

Thus, to design a seroprevalence study at wereda level in Ethiopia, the clustering effect of the kebelles implies the sample size has to be increased by a factor of 1.26 if 10 small ruminants are to be sampled per kebelle, 1.55 if 20 small ruminants are to be sampled, 2.42 if 50 are sampled and 3.87 if a hundred small ruminants are to be sampled in each selected kebelle. Our findings are in agreement with other published values for $\rho$ and $D$ related to viral diseases or vector-borne infections. Thus the majority of $\rho$ reported lay below 0.20 with widely varying estimates for highly contagious viral infections as Infectious bovine rhinotracheitis (IBR) [38]. To our knowledge no specific reference was available until now for peste des petits ruminants.

\section{Conclusion}

Our study shows that PPR has extensively circulated across Ethiopia, but that there is large variation between regions and weredas. Although in most weredas there is a small variation between kebelles in some of them there are large differences that indicate the virus has only been introduced recently among some kebelles of the wereda, if our interpretation of high intracluster correlation coefficients as indicative of more recent introduction is valid, PPRV has been more recently circulating in the North of the country. The results of our study indicate that further research is needed to investigate the association of the presence of disease with the management practices in place. These findings are also important to direct future studies in other countries where PPR is of importance. 


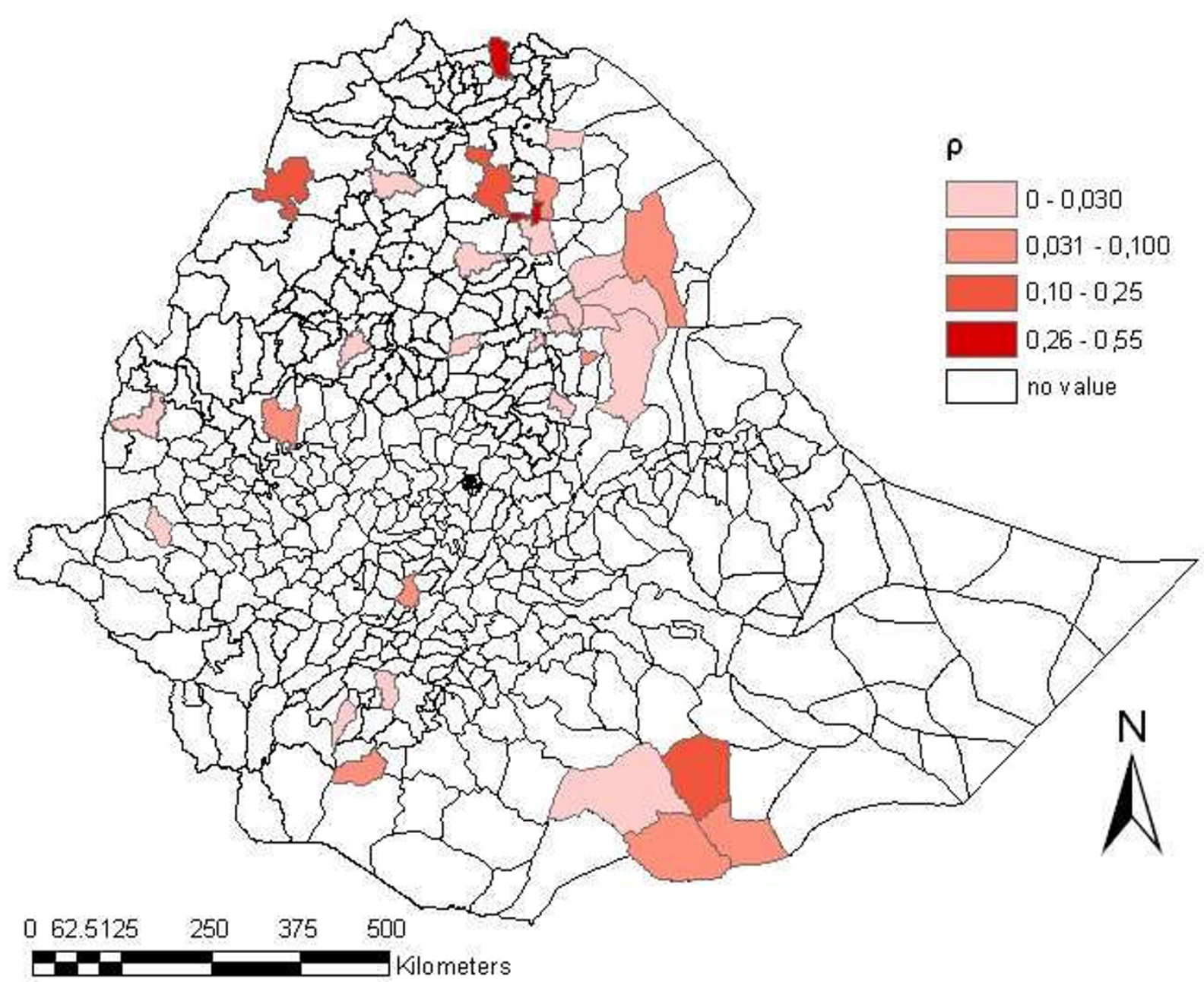

Figure 3

Distribution of wereda $\rho$ values across Ethiopia in 1999. Geographical distribution of the values for the intra-cluster correlation coefficient $(\rho)$ by wereda. The red is more intense in the weredas with a higher value for $\rho$.

\section{Abbreviations}

ADB: African Development Bank; cDNA: complementary DeoxyriboNucleic Acid; cELISA: competitive EnzymeLinked Immunosorbent Assay; EDI: ELISA Data Information; FAO: Food and Agriculture Organization; GDP: Gross Domestic Product; IAEA: International Atomic Energy Agency; IBR: Infectious Bovine Rhinotracheitis; NAHRC: National Animal Health Research Center; NLDP: National Livestock Development Project; OD: Optical Density; PI: Percentage Inhibition; PPR: Peste des Petits
Ruminants; PPRV: Peste des Petits Ruminants virus; $\rho$ : intracluster correlation coefficient.

\section{Authors' contributions}

AWS, DC and LMY collected the data, created the electronic database and cleaned and processed the data for analysis. AWS and JG conceived and performed the data analysis. AWS drafted the manuscript assisted by JG. FR, DUP and GL raised funding for the study and assisted its coordination. All authors helped with the interpretation of the results and read and approved the final manuscript. 


\section{Acknowledgements}

We are grateful for the access to data and practical support given by the National Animal Research Health Center (Ethiopia), in particular its Director Dr Mesfin and Dr Abraham Gopilo. The authors would also like to thank Dr Berhe Gebreeziabher who facilitated the data collection and interpretation of results.

This study was carried out in the frame of the EU funded INCO-CT-2004003670 RP/PPR MARKVAC project.

\section{References}

I. Barrett T, Visser IKG, Mamaeu L, Goatley L, Bressem MF, Van Osterhaus ADM: Dolphin and porpoise morbilliviruses are genetically distinct from phocine distemper virus. Virology 1993, 193:1010-1012.

2. Jones L, Giavedoni L, Saliki JT, Brown C, Mebus C, Yilma T: Protection of goat against peste des petits ruminants with a vaccinia virus double recombinant expressing the $F$ and $H$ genes of rinderpest virus. Vaccine 1993, I I:961-964.

3. Scott GR: Rinderpest and Peste des petits ruminants. In Virus disease of food animals Volume 2. Edited by: Gibbs EPJ. London: Academic Press; 1981:401-432.

4. Yayehrad TF: Epidemiological survey of Peste des petits ruminants and Contagious pleuropneumonia in selected areas of Ethiopia. In Doctor in Veterinary Medicine thesis Debre Zeit Faculty of Veterinary Medicine; 1997.

5. Akakpo AJ, Deconinck P, Amegatse K, Kaboret Y, Oudar J: Une épidémie de la Peste des petits ruminants (PPR) en élevage périurbain à Dakar: importance épidémiologique et médicale. Rev Med Vet 1996, 147:447-452.

6. Diallo A: Peste des petits ruminants. In Principales maladies infectieuses et parasitaires du bétail. Europe et régions chaudes. Tome I: Généralités: Maladies virales Edited by: Paris: Lavoisier. Lefèvre PC, Blancou J, Chermette R; 2003:307-322.

7. Nanda YP, Chatterjee A, Purohit AK, Diallo A, Innui K, Sharma RN, Libeau G, Thevasagayam JA, Bruning A, Kitching RP, Anderson J, Barrett $T$, Taylor WP: The isolation of peste des petits ruminants virus from northern India. Vet Microbiol 1996, 5 I:207-2 I6.

8. OIE [http://www.oie.int/fr/maladies/fiches/f A050.htm]

9. Pegram RG, Tereke F: Observation on the health of Afar livestock. Ethiopian Vet J I98I, 5: I I-4.

10. Wakwaya K: Epidemiological and serological investigations on ovine respiratory diseases and observation on vaccinated sheep on the Highland of North Shoa/Sheno. In Doctor in Veterinary Medicine Thesis Debre Zeit Faculty of Veterinary Medicine; 1997.

II. Gargadennec L, Lalanne A: La peste des petits ruminants. Bull Serv Zoot Epiz AOF 1942, 5(I): I6-21.

12. Gopilo A: Epidemiology of Peste des Petits Ruminants virus in Ethiopia and molecular studies on virulence. In PhD thesis Institut National Polytechnique de Toulouse; 2005.

13. Lefevre PC, Diallo A: Peste des petits ruminants. Rev Sci off int Epiz 1990, 9(4):951-965.

14. Shaila MS, Shamaki D, Foryth MA, Diallo A, Goatley L, Kitching RP, Barrett T: Geographical distribution and epidemiology of PPR viruses. Virus Res 1996, 43:149-153.

15. Lefevre PC, Diallo A, Schenkel F, Hussein S, Staak G: Serological evidence of peste des petits ruminants in Jordan. Vet $\operatorname{Rec} 1991$, 1 28: II0.

16. Ozkul A, Akca Y, Alkan F, Barrett T, Karaoglu T, Dagalp SB, Anderson J, Yesilbag K, Cokcaliskan C, Gensay A, Burgu I: Prevalence, distribution, and host range of Peste des petits ruminants virus, Turkey. Emerg Infect Dis 2002, 8:708-7I2.

17. Singh RP, Saravanan P, Sreenivasa BP, Singh RK, Bandyopadhyay SK: Prevalence and distribution of peste des petits ruminants (PPR) virus infection in small ruminants of India. Rev sci tech Off int Epiz 2004, 23(3):807-819.

18. Taylor WP, Al Busaidy S, Barrett T: The epidemiology of peste des petits ruminants in the Sultanate of Oman. Vet Microbiol 22:341-352.

19. Diallo A: Vaccination for the Control of Peste des Petits Ruminants. In Control of Infectious Animal Diseases by Vaccination: 1316 April 2004; Buenos Aires, Argentina Edited by: Schudel A, Lombard M. Bale: Karger; 2004:93-98.
20. Libeau G, Diallo A, Minet C, Berhe G, Le Goff C, Hurard C, Grillet C, Kwiatek $O$, Roger $F$, Albina $E$ : La peste des petits ruminants (PPR): diagnostic et contrôle en 2002. Book of abstracts, World Veterinary Congress 27th 2002. 25-29 September 2002

21. Couacy-Hymann E, Bidjeh K, Angba A, Domenech J, Diallo A: Protection of goats against rinderpest by vaccination with attenuated peste des petits ruminants virus. Research in Veterinary Science 1995, 59:106-109.

22. Diallo A, Taylor WP, Lefèvre PC, et Provost A: Atténuation d'une souche de virus de la peste des petits ruminants: candidat pour un vaccin homologue vivant. Rev Elev Méd vét Pays trop 1989, 42:31|-319.

23. FAO: Le Bulletin EMPRES des maladies animales transfrontalières. Bulletin no2 - juillet 1997. 1997.

24. FAOSTAT database [http://faostat.fao.org]

25. CSA (Central Statistical Agency): Agricultural sample survey 2005/2006 [I 998 E.C.], Report on livestock and livestock characteristics. Statistical bulletin $n^{\circ} 36$ I Volume II. Addis Ababa; 2006.

26. Alemayehu Z, Fletcher I: Small ruminants productivity in the central Ethiopia mixed farming systems Addis Ababa: IAR (Institute of Agricultural Research); 1991.

27. Tibbo M: Productivity and Health of Indegenous Sheep breeds and crossbreds in the Central Ethiopian Highlands. In PhD Thesis Swedish University of Agricultural Sciences, Uppsala; 2006.

28. ILCA (International Livestock Center for Africa): Handbook of African Livestock Statistics Addis Ababa; 1993.

29. Roeder PL, Abraham G, Kenfe, Barrett T: PPR in Ethiopian goats. Trop Anim Hlth Prod 1994, 26(2):69-73.

30. Gelagay A: Epidemiological and serological investigation of multi-factorial ovine respiratory disease and vaccine trial on the high land of North Shewa, Ethiopia. In Doctor in Veterinary Medicine Thesis Debre Zeit Faculty of Veterinary Medicine; 1996.

31. Abraham G, Sintayehu A, Libeau G, Albina E, Roger F, Laekemariam $Y$, Abayneh D, Awoke KM: Antibody seroprevalences against peste des petits ruminants (PPR) virus in camels, cattle, goats and sheep in Ethiopia. Prev Vet Med 2005, 70(1-2):5 I-7.

32. Anonymous: Grand Atlas du continent Africain Paris: Edition Jeune Afrique; 1973.

33. Mukasa Mugerwa E, Lahlou-Kassi A: Reproductive performance and productivity of Menz sheep in the Ethiopian highlands. Small Ruminants Research 1995, I7:167-177.

34. Choi K, Nah J, Ko Y, Kang S, Jo N: Rapid competitive Enzyme Linked Immunosorbent Assay for detection of antibodies to Peste des Petits Ruminants virus. Clinical and Diagnostic Laboratory Immunology 2005, I 2(4):524-547.

35. Singh RP, Sreenivasa BP, Dhar P, Shah LC, Bandyopadhyay SK: Development of a monoclonal antibody based competitive ELISA for the detection and titration of antibodies to peste des petits ruminants virus. Vet Microbiol 2004, 98(I):3-I5.

36. Branscum AJ, Gardner IA, Wagner BA, Mclnturff PS, Salman MD: Effect of diagnostic testing error on intracluster correlation coefficient estimation. Preventive Veterinary Medicine 2005, 69:63-75.

37. Campbell MK, Grimshaw JM, Elbourne DR: Intracluster correlation coefficients in cluster randomized trials: empirical insights into how should they be reported. BMC Medical Research Methodology 2004, 4:9.

38. Otte MJ, Gumm ID: Intra-cluster correlation coefficients of 20 infections calculated from the results of cluster-sample surveys. Preventive Veterinary Medicine 1997, 3 I: I47-I 50. 